\title{
Code-Switching for Bilingual Students
}

\author{
Yu Sun \\ School of Literature, Law and Foreign Languages \\ Wuchang University of Technology \\ Wuhan 430223, Hubei, China
}

\begin{abstract}
Code-switching has been an important research topic in many disciplines: sociology, psychology, linguistics. This paper selected 20 postgraduate students from Hong Kong, China and Singapore, randomly selected from a group of four, to create a free talk environment for them, give them a specific topic for dialogue and discussion, then record their conversations. After that, analyze the obtained corpus and a conclusion is drawn. How code-switching effects Hong Kong, Singapore bilinguals, and, takes several college bilingual students (whom from Hong Kong and Singapore) for conversation survey. This research is based on the theory of adaptability. By lists phenomena of code-switching and analyzing daily corpora, it further enriches the theoretical framework of code-switching motivation.
\end{abstract}

Keywords-code switching; bilingual students; case study; conversational analysis approach

\section{INTRODUCTION}

Several studies on how bilingual language users to process languages have been reported. Basically, Hong Kong was a colony of the British empire for 156 years, at the middle 1980s, the British colonial government gradually increased the number of University Students, English users, especially young people, begin to speak English in their daily life. Singapore is an island in Southeast Asia. It lies at the southern tip of the Malay Peninsula and is home to 5.6 million residents. Singapore has four national languages: English, Malay, Mandarin and Tamil. Most Singaporeans are bilingual.

Code-switching has three different types: Poplack's inter-sentential, intra-sentential and tag switching. This paper shows how two languages are combined with ordinary life and being used by bilinguals. Holmes states that it is easier for some people to discuss a particular topic by switching to another code. The language speakers choose language code to be used in their communication, sometimes switching from one to another code for convenience or explain some code.

A local accent may be either positively or negatively valued. Hudson says "your dialect shows who (or what) you are, whilst your register shows what you are doing." He acknowledges that "these concepts are much less distinct than the slogan implies"; however, you might use them to discuss the relationship between a dialect and its standard variety, what are the possible contexts for the dialect and what are the functions and effects of using it.

Hudson says that "lay people sometimes ask linguists questions such as 'Where is real Cockney spoken?' They assume such questions are meaningful. (Another is 'Is Jamaican creole a kind of English or not?') Hudson says such questions "are not the kind of questions that can be investigated scientifically."

Code-switching is a phenomenon of language contact. It is treated as a negative factor that affects language learning in Hong Kong. For this reason, code-switching is prohibited in school education. Also, in China, code-mixing is spreading, particularly in coastal areas.

Some loan words in Hong Kong and Singapore are the results of the transcription of foreign words, such as spanner, microphone, bus, taxi. Basil Bernstein concludes that the restricted code is associated with one's linguistic competence.

Early British colonists came to Singapore in the 19th century, where they set up schools and people began to learn English. In the early time, the English that the Singaporeans said was not a formal English, the researcher can consider it as a mixed-language spoken by people who could not speak English. At that time, Singapore's English grammar was relatively simple, their pronunciation was not very stable, and the non-English ingredients were very large, including the influence of Indian English, Nyonya Malay, Chinese, Fujian dialect, and Cantonese. Later, as time went by, a new generation of Singaporeans began to learn English as their native language. Afterward, vocabulary, pronunciation, grammar, etc. gradually matured and matured, eventually forming a fully mature English dialect, which is what we now call Singapore English. From the root, British English is the root of Singapore English, so the two are very similar, they can communicate with each other, but unfortunately, they cannot fully understand each other. Singapore English is actually a dialect that evolved from traditional English, or it can be understood as English with a Singapore accent.

To help newcomers integrate into Singapore as soon as possible, the TalkingCock.com website has compiled a compelling "The Coxford Singlish Dictionary" for Singapore English and has also published an online version on its website as we can see it in TABLE I, but it is not a standard authority dictionary. Even spelling is not uniform. But this is the true Singapore English, and we can also understand as code-switching.

TABLE I. AN ESSENTIAL GUIDE TO SINGLISH

\begin{tabular}{|c|c|c|}
\hline Can lah & - & Yes. \\
\hline Can leh & - & Yes, of course. \\
\hline Can lor & - & Yes, I think so. \\
\hline Can hah? & - & Are you sure? \\
\hline Can hor & - & Are you sure then? \\
\hline Can meh? & - & Are you certain? \\
\hline
\end{tabular}


As a former British colony, Hong Kong's English education is highly valued, and even most schools use English as a language of instruction. Therefore, the popularity of English in Hong Kong is also high. After the return in 1997, Hong Kong is still an international metropolis where people from all over the world come together. Everyone's language is different, and English is the official language of the world. Therefore, the frequency of English use is relatively high, and the application is wide, especially in the business environment, as well as some technical terms. In order to express and communicate more efficiently and accurately, everyone has formed such a way of speaking.

Thus, code-switching is very helpful for students to solve the difficulty in using English, the limitation of native vocabulary also is the reason why they switch code, in additional, English lecturers can create comfortable in teaching by using code-switching.

\section{METHOD}

\section{A. Participants}

For the study the code-switching phenomenon, we have to collect the corpus first. For corpus collecting, we often use written language and oral language. The first one mostly from print media, the second one mostly a record of natural communicative language. Written language cannot update in every minute, and artistic processing makes it lack of realism; oral language can be used in ordinary life, its real and controllable.

This study selects several second-year postgraduate students from a foreign language university in China, who from Hong Kong and Singapore. On the one hand, the students of foreign language colleges have a strong language learning atmosphere and we provide a more relaxed environment for them to using the language. On the other hand, all these students are bilinguals, they all have a high level of language, and have also, high communication skills. A total of 20 study subjects were asked to interview each other in groups of four. The samples include students from Hong Kong and Singapore from different majors. Some of them know each other and some have never met, but similar backgrounds and experiences help the natural generation of code conversion. Finally, at the end of our interview, one interviewee was randomly selected from the five groups to briefly summarize the whole interview.

The basic information of the interviewees is shown in TABLE II.

TABLE II. BRIEF PROFILE OF RESPONDENTS

\begin{tabular}{|c|c|c|c|}
\hline Group & Gender & Birthplace & Major \\
\hline 1 & $\begin{array}{c}\text { Female } 2 \\
\text { Male } 2 \\
\end{array}$ & Hong Kong 4 & $\begin{array}{c}\text { Chinese language and literature } 2 \\
\text { Business English } 2 \\
\end{array}$ \\
\hline 2 & $\begin{array}{c}\text { Female } 3 \\
\text { Male } 1 \\
\end{array}$ & $\begin{array}{c}\text { Hong Kong } 3 \\
\text { Singapore } 1 \\
\end{array}$ & $\begin{array}{c}\text { Business English } 3 \\
\text { Advanced Information System } 1 \\
\end{array}$ \\
\hline 3 & $\begin{array}{c}\text { Female } 1 \\
\text { Male } 3\end{array}$ & Singapore 4 & $\begin{array}{c}\text { Chinese language and literature } 3 \\
\text { Agronomy } 1\end{array}$ \\
\hline 4 & $\begin{array}{c}\text { Female } 3 \\
\text { Male } 1 \\
\end{array}$ & $\begin{array}{l}\text { Hong Kong2 } \\
\text { Singapore } 2 \\
\end{array}$ & International Education4 \\
\hline 5 & $\begin{array}{c}\text { Female } 2 \\
\text { Male } 2\end{array}$ & $\begin{array}{l}\text { Hong Kong3 } \\
\text { Singapore } 1\end{array}$ & $\begin{array}{c}\text { Chinese language and literature } 2 \\
\text { International Education } 2\end{array}$ \\
\hline
\end{tabular}

\section{B. Procedures}

This study collected corpora through observations and interviews. The corpus is mainly from the daily conversation of 20 respondents. In addition, the corpus also includes specific situations, such as dialogues and communication of opinions that require respondents to express an opinion. In this corpus collection, the author made a detailed record of the dialogue between the participants in the interview, especially the use of code conversion in real dialogues. The recording tools include digital voice recorders, notebooks, cameras, etc.

The researcher collected the data by doing direct observation and can record all of the activities of the interviewees by using video camera. Digital voice recorders and digital cameras produce good quality of the recording. First of all, all the interviewees have been divided into five groups, put every group in separate classroom, the researcher came to record the classroom activity. The length of video recording will be varied, the differences in the recording pieces will be appeared because of different activities in the classroom. The researcher is a non-participative member, he just stays at the other room and view the screen, and recording what happened during the five classrooms.

\section{RESUlT AND DISCUSSION}

Group 1 Student A (from Hong Kong, female, Chinese language and literature): "The four people in my group all come from Hong Kong, but we are in Different Districts. More than $80 \%$ of our chats are in Cantonese, and sometimes we use English to replace some key words that are difficult to express in Cantonese. Some words in English are easier to express in terms of people's mood. In addition, the four of us have in common with the love of watching the American TV series The Big Bang Theory. We recapitulate the classic lines of the actors in TV dramas in English. But in daily life, I am still not used to encounter the phenomenon of code-switching. For I am a student of Chinese language majors, sometimes English majors speak one less common English directly in when we were talking. I still need some time to guess what does the word means. May be that the code-switching phenomenon is more common for English majors, but it still affects communication for students who are not in this major."

Group 2 Student B (from Hong Kong, male, Business English): "The three Hong Kong people in our group are majoring in Business English, one Singaporean is majoring in IT, English is the official language of Singapore, so she can speak English pretty well. Therefore, our group basically uses English for dialogue, with a small amount Cantonese, Singaporean can understand Cantonese and can also speak Mandarin. The whole dialogue process was relatively pleasant, especially the Singaporean student was able to perform code-switching fluently, reflecting her excellent language skills. Sometimes someone talks to a specific term in a certain field. If other people don't use the term often, they really cannot get it. At this time, we will reconfirm in Cantonese or Mandarin so that they can understand each other. Since everyone in our group is proficient English user, I feel very pleased to talk directly in English, and double-check with code-switching, insure there will not misunderstand." 
Group 3 Student C (from Singapore, male, Agronomy): "The four people in my group all come from Singapore, Singapore is a very small country, after the conversation, we find that we live very close in Singapore, the two of us were even graduated from the same high school. The three people in our group are specializing in Chinese language and literature. They can perform fluent Chinese-English code-switching, and can read very famous ancient poems in Mandarin. I don't understand the actual meaning of the poems, so I didn't speak much. And their undergraduate studies are in Chinese language and literature, too. So, in my opinion, more than $80 \%$ of the dialogues are in Chinese. Only when it comes to the topic of the old days living in Singapore, English will be used. However, since my high school is not in the central area, my English education background is not very good. I used to communicate with my friends and families in Singapore with Singapore English mixed with Hakka dialects. Therefore, I encountered a conversation between Mandarin and English. This kind of conversation, for me, is a bit difficult to accept.”

Group 4 Student D (from Singapore, male, International Education): "The four people in our group are in the same Major, so we knew each other before. But I didn't talk with them specifically. The theme of our talk this time was to introduce famous tourist places and recommended snacks in Hong Kong and Singapore. We used about half Mandarin and half English for the whole process. Since the International Education profession trains our English and Chinese Mandarin, if the previous speaker uses Mandarin, the next speaker will basically use Mandarin. Sometimes one person's switch to a proper word in English, then the next person will also use English. It's normal because we share the same Major, and the target languages have intersections, so it's natural for us to perform code-switching, and it won't look intentional or sudden.”

Group 5 Student E (from Singapore, female, Chinese language and literature): "The theme of our conversation is about interviews after graduation. We think that if you continue to mix English with Chinese when attending a job interview, the interviewer may have an adverse effect, and the interviewer's first impression of him will definitely bad. He may use Chinese-English code-switching naturally, but in the eyes of others, it should be very uncomfortable. I think the code-switching should be neutral in our daily life. The main thing is what is the psychological feeling of the person doing the code conversion and his audience. For example, four people in our group can speak English and Mandarin fluently. When chatting, we can also naturally switch between Chinese and English. The code-switching can even help to express the meaning of the discourse and help the communication be completed more smoothly."

\section{ANALYSIS}

For 12 Hong Kong students, loanwords are their biggest problem. Loanwords are interesting in that they not only provide a glimpse into language contact; they also reveal the process of how a language acquires new words. Historical contact between English and Cantonese began in the late 17th century when British traders came to Guangzhou to buy Chinese tea and porcelain. English loanwords are documented in the first English-Cantonese, Cantonese-English dictionary published in 1828. The loanwords in their daily language have special pronunciation, they used to use wrong pronunciation. When they use the loanwords, they always make the audience confused, not just Hong Kong student, Japanese and Korean students also have this loanword problem.

In this study, out of the 20 participants, the researcher found that people with better language skills have higher professionalism in their majors. Such as Group 3, the boy specializing in Agronomy. After the chatting, he feels that his academic pressure is higher than his peers in Group 3. The university lecturer teaches in English. Although he is Singaporean, he is not proficient in standard English grammar and word usage. Sometimes the teacher used code-switching to explain an incomprehensible part, he could not understand the teacher's Mandarin. The lack of language ability directly affected his studies.

When people talking about sensitive or negative content, they often adopt strategies such as skipping quickly or changing topics to avoid others' embarrassment or unpleasantness. In this way, code-switching becomes a common strategy. On the one hand, it can avoid the risks brought by direct answering. On the other hand, it can keep the topic going and keep the dialogue relatively private. In the process of interpersonal communication, the speaker can also save the face of the other party through the code conversion to minimize the negative impact and avoid the deterioration of the relationship. If the other party finds that they cannot understand what they are talking about in English, they can quickly perform the code Conversion, explain difficult words in Mandarin, and save face for the other, not embarrassing.

\section{CONCLUSION}

The code-switching of Cantonese and English in Hong Kong is mainly Cantonese-Chinese form, and English words or phrases are inserted into it. The reasons for code-switching in Hong Kong are many and complex. There are both semantic and psycho linguistic and social languages in terms of science. Which must be pointed out is that, in a certain context, which one or a group of factors is the main cause, it depends on the specific context. In particular, the following variables have the most influence and are most obvious: the identity of the audience, the age of the audience, the education background of the audience, the purpose of the speaker, the effect the speaker needs to achieve, and the occasion (formal or informal where the speaker speaks), Etc., it is certain that the code switching between Cantonese and English has become an important part of the language of Hong Kong people.

Although the official language of Singapore is English, the English ability of the Singapore students interviewed this time is not satisfactory. The level of English education received by respondents from one's primary school to high school, which is directly related to their English proficiency after the college period. If one accustomed to speaking Hakka and Fujian dialects in daily life, can only use English code switching to simply describe some English words or phrases, which will inevitably lead to a low level of English and unable to have a direct conversation with native English speakers. In addition, 
conversion is a natural language phenomenon, but they believe

the pronunciation of the Hakka dialect Fujian also affects English pronunciation.

This research is based on the theory of adaptability. By analyzing daily corpora, it further enriches the theoretical framework of code-switching motivation. Through this study, it is found that students' motivations for daily reputation conversion are divided into three categories: adaptation to linguistic reality, adaptation to social conventions, and adaptation to psychological conditions. These three categories can be further divided from the perspectives of language, theme, and intention: conforming to language gaps and fixed expression patterns, conforming to the themes and language authority, active atmosphere, showing affinity, seeking convenience, and facilitating expression. In conformity with language reality, social conventions and psychological conditions are the intrinsic driving forces of bilingual students' code switching. Language is associated with groups of users, specific activities, discourse functions, and more. Code switching can change the language environment, make formal occasions informal, relax the serious atmosphere, and make the hierarchical relationships free and equal. These are all things you can't do in English or Mandarin. Exploring the motivation of bilinguals' code-switching helps to better understand the speaker's thinking mode and examine the use of language. In this study, the vast majority of respondents expressed positive attitudes towards code-switching and thought that Code that in university classrooms, code switching should be avoided as much as possible to create an academic atmosphere in the university. Teachers' code-switching in the classroom can have a direct impact on students, and this impact may be negative, which should have implications for the future development of English teaching systems. Bilinguals are pioneers in cross-lingual communication. Their language skills directly determine whether they can receive the most orthodox and authentic education. So, studying their language usage is extremely meaningful.

\section{REFERENCES}

[1] Cindy L. Gunn. 2003. Exploring second language communicative competence.

[2] Christina Bratt Paulston. 1974. Linguistic and communicative competence.

[3] Diane Larsen. 2012. From unity to Diversity: twenty-five years of language-teaching methodology.

[4] Monica. L. Bellon-Harn and William E Harn. 2006. Profiles of social-communicative competence in middle school children with Asperger syndrome: Two case studies.

[5] M. L. Vergne. 1982. Verbs and communicative competence.

[6] Nadjmuddin M. The Use of Code-Switching and Code-Mixing in English Language Teaching at state Polytechnic of Sriwijaya[J]. Holistic, 2012. 